\title{
Precipitation estimation performance by Global Satellite Mapping and its dependence on wind over northern Vietnam
}

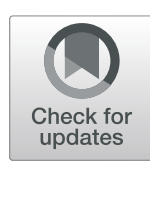

Masato I. Nodzu ${ }^{1 *}$ (D, Jun Matsumoto ${ }^{1,2}$, Long Trinh-Tuan ${ }^{3}$ and Thanh Ngo-Duc ${ }^{3}$

\begin{abstract}
The performance of the Global Satellite Mapping of Precipitation data Microwave-Infrared Combined Reanalysis Product (GSMaP RNL), version 6, was evaluated, using northern Vietnam as the test area. The Vietnam Gridded Precipitation (VnGP) Dataset was used for comparison purposes. Particular emphasis was placed on the investigation of heavy-rain days (precipitation over $50 \mathrm{~mm}$ day $^{-1}$ ). Wind data from operational radiosonde observations at Hanoi were also used to examine the effect of interaction between wind and topography, on the GSMaP performance, and the basic relationship between the VnGP precipitation and lower tropospheric wind. Results showed that heavy-rain days generally occurred during May-August. Regions with higher and lower precipitation in the GSMaP, compared to the VnGP, were found to be distributed in a complex manner, at a scale similar to that of tributary basins. The GSMaP and the VnGP showed similar precipitation values when associated with westerly wind in the lower troposphere at Hanoi. Positive influences of westerly wind on estimated precipitation were observed along the northeastern foot of the mountain ranges, whereas negative influences were found along the southeastern foot. The results implied that the GSMaP rainfall estimation algorithm, taking account of orographic effects, may improve the accuracy of rainfall reproducibility, by using a more appropriate wind dataset to evaluate orographic convection.
\end{abstract}

Keywords: Precipitation, Satellite observation, GSMaP, Asian summer monsoon, Orographic convection

\section{Introduction}

Hanoi, the capital of Vietnam, is located on the Red River Delta. The Red River runs southeastward from southern China through mountainous regions to the Gulf of Tonkin in northern Vietnam (Fig. 1). Northern Vietnam, located on the eastern part of the Indochina Peninsula, and facing the South China Sea (SCS), is subdivided into several independent river basins. This peculiar topography interacts with the lower-tropospheric southwesterly monsoonal flow, which rapidly expands northeastward in the early boreal summer over the peninsula, resulting in an early rainy season, in mid-May (Matsumoto (1997); Wang and LinHo (2002); Zhang et al. (2002); Chang et al. (2005); Nguyen-Le et al. $(2014,2015))$. Northern Vietnam is also strongly and frequently affected by

${ }^{*}$ Correspondence: nodzum@tmu.ac.jp

'Department of Geography, Tokyo Metropolitan University, 1-1 Minami Ohsawa, Hachioji, Tokyo 192-0397, Japan

Full list of author information is available at the end of the article tropical cyclones generated over the SCS and the western North Pacific (Nguyen-Thi et al. 2012).

Overall, the regional rainfall climatology is affected by the summer monsoon system, by tropical cyclones and by the region's topography-and in turn strongly affects human activities, such as forestry, agriculture, transportation, and energy. Both scientific interest and the importance of rainfall to the economy and to society have made Vietnamese rainfall a topic of research interest for several decades.

Infrastructure in the growing urban area of Hanoi and its hinterland is vulnerable to flooding by the Red River, which is also a valuable water resource. A good understanding and accurate forecasts of the hydrological behavior of the Red River will favor both further economic development and hydrological disaster prevention, in northern Vietnam. Accurate precipitation information is required in order to develop hydrological information sufficiently accurate to form the basis for enhancing 


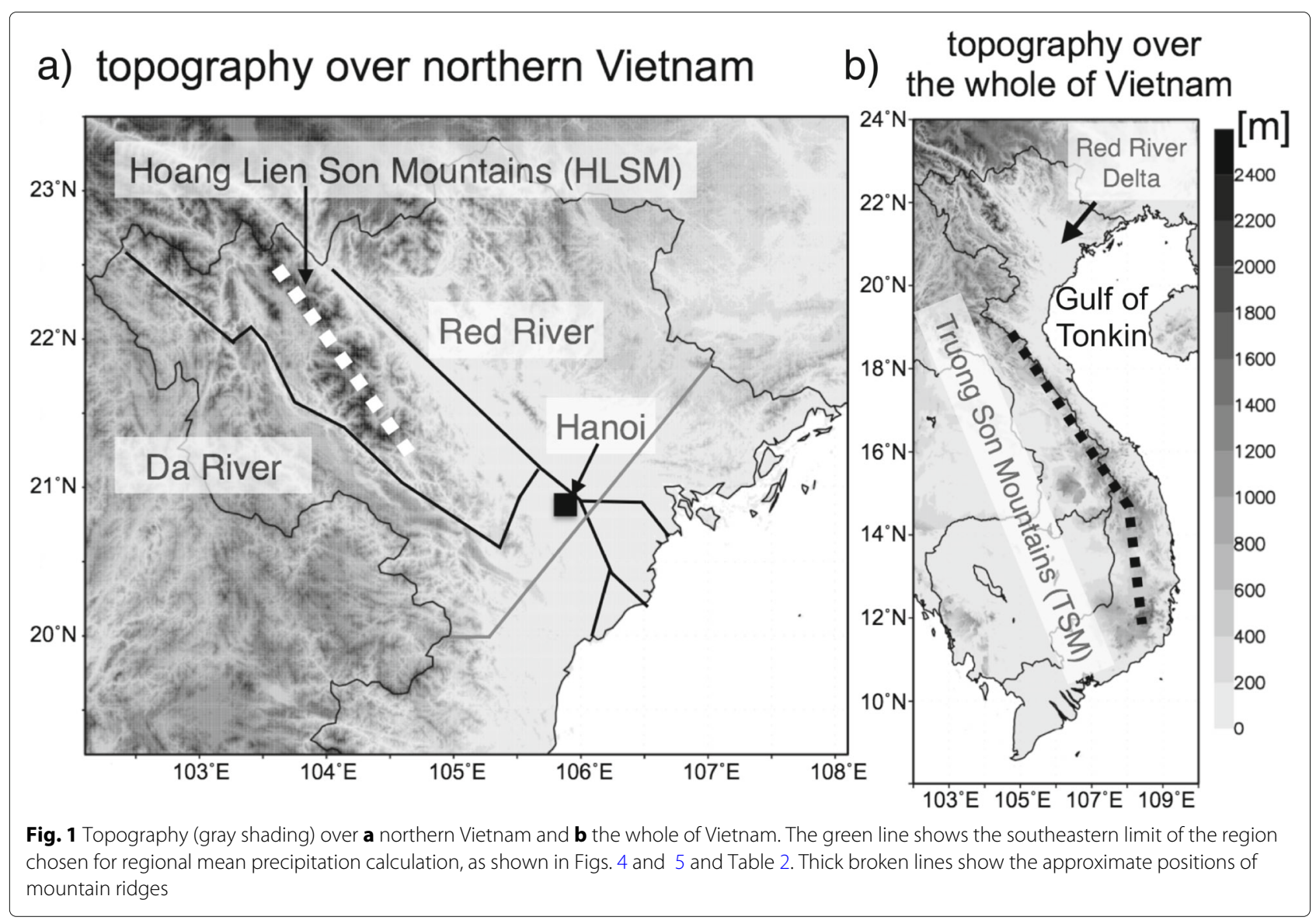

the river's positive effects, while allowing mitigation of negative effects.

Although surface rain gauge observations give direct precipitation data, their spatial resolution is not fine enough to model hydrological behavior accurately. The other weak point with gauge observation is the difficulty of real-time data collection for forecasting purposes. Satellite observation is a powerful and promising new tool to complement gauge observations, although issues remain in the application of satellite precipitation data. When used in hydrological models, the greatest difficulty is in coping with the error classes introduced by varying seasonality, topography, and regionality (Maggioni and Massari 2018). Dealing with these potential errors requires individual calibration methods being fitted into the specific situations responsible for the satellite precipitation data errors. Poor performance over mountainous and coastal regions is a typical issue (McCollum and Ferraro (2005); Kubota et al. (2007); Ngo-Duc et al. (2013); Shige et al. (2013); Mega and Shige (2016)). In such regions, one of the reasons for the poor performance is orographic convection, with relatively low cloud tops caused by the interaction between low-level winds and topographic barriers. Orographic convection sometimes brings heavy rainfall, even though its convective top is low, and researchers have tried to improve representation of this kind of convection (e.g., Kwon et al. (2008)). Ngo-Duc et al. (2013) improved monthly precipitation data from the Global Satellite Mapping of Precipitation (GSMaP; Aonashi et al. (2009); Ushio et al. (2009)) with a corrective method applying an artificial neural network over central Vietnam. Yamamoto and Shige (2015) (hereafter YS15) introduced an algorithm to distinguish orographic rainfall in the GSMaP.

Among several satellite precipitation datasets, the GSMaP has been shown to agree relatively well with surface rainfall observations over central Vietnam, at multiple spatial and temporal scales (Trinh-Tuan et al. (2019), under review). It also creates better outcomes by combining infrared radiometer and passive microwave data with a wider observational range (e.g., Kummerow et al. (1998)), supported by radiative transfer model simulations (Aonashi et al. 2009) and propagation forecasts, using two successive infrared images, in a Kalman filter model.

In this way, the GSMaP accounts for orographic convection well, and its characteristics are known over mountainous regions in central Vietnam, with its relatively simple landforms, through previous studies. It is thus considered that the GSMaP should be applicable to 
hydrological forecasts over northern Vietnam, including the Red River basin region.

To check the GSMaP applicability in this way, the first priority was to understand differences between the surface gauge and the GSMaP data, for those heavy-rain events that can cause serious disasters. The purpose of this study, therefore, is to obtain basic knowledge on satellite precipitation data, to potentially improve realtime hydrological forecasting, focusing on heavy-rain events over northern Vietnam, at a daily time scale. The GSMaP, the Vietnam Gridded Precipitation (VnGP) Dataset (Nguyen-Xuan et al. 2016), produced from rain gauge measurement, and operational radiosonde data for Hanoi are utilized to investigate satellite-based precipitation estimate performance, and its dependence on wind for heavy-rain events. We also included basic analyses to elucidate features of lower-tropospheric wind, and the relationship between wind and precipitation.

\section{Data and methods}

\section{Data}

The daily rainfall data used were the GSMaP MicrowaveInfrared Combined Reanalysis Product (GSMaP RNL), version 6 , and the VnGP, as satellite- and surfaceobservation-based datasets, respectively.

The GSMaP is a global rainfall dataset, based on passive microwave and infrared radiometer data, which is produced and distributed by the Earth Observation Research Center (EORC), Japan Aerospace Exploration Agency (JAXA). It is supported by JST-CREST and promoted by the JAXA PMM Science Team. Its algorithm makes use of attribute data obtained from the Tropical Rainfall Measuring Mission (TRMM) Precipitation Radar. The reanalysis product, GSMaP RNL, has been produced with the newly developed algorithm, version 6, for the Global Precipitation Measurement (GPM) mission, and has been applied to the period before March 2014, to provide data alternative to the standard product, GSMaP MVK. The version 6 algorithm includes an orographic rainfall correction method, for warm rainfall in coastal areas (Shige et al. 2013; YS15).

The GSMaP horizontal and temporal resolutions are $0.1^{\circ}$ latitude/longitude and hourly, respectively. The GSMaP data were used as daily data-as $24 \mathrm{~h}$ accumulated hourly data, from 19 LT (12 UTC) of the previous day, matched with the VnGP data, as mentioned below. The GSMaP RNL data used covered the period from Mar. 2000 to Feb. 2014.

The VnGP Dataset (Nguyen-Xuan et al. 2016) was used to determine heavy-rain event seasonality and to groundtruth daily precipitation data, as part of the GSMaP data performance evaluation process. The dataset was constructed using rain gauge data from 481 Vietnam Meteorological Hydrological Administration (VMHA) stations, using the Spheremap interpolation method (Willmott et al. 1985), modified for spherical coordinates, and based on the weighted horizontal interpolation algorithm introduced by Shepard (1968). The VnGP Dataset has the same horizontal resolution as the GSMaP ( $0.1^{\circ}$ latitude/longitude) and covers 31 years, from 1980 to 2010.

Data covering the period May 2000 to Dec. 2010—which was the longest period of GSMaP RNL/VnGP overlapwere used in our analysis. The data for 2001-2010 were used to examine the seasonality of heavy-rain day occurrence, and for general comparison between the VnGP and the GSMaP, as illustrated in Figs. 2 and 3. As the analyses focused just on May-Aug. data for each year, we used the VnGP, the GSMaP, and zonal wind data covering those months, for 2000-2010, in Figs. 4, 5, and 6.

We utilized wind data of the operational GPS radiosonde observation at Hanoi at 07 LT (00 UTC), which corresponds to the middle time of the GSMaP and the VnGP daily precipitation. Six-hourly wind in the objective reanalysis data JRA-55 (Kobayashi et al. (2015); Harada et al. (2016)), at the $850 \mathrm{hPa}$ level, was also used to confirm the GSMaP performance sensitivity in relation to wind. Topographic data were taken from Global Land One-km Base Elevation (GLOBE) data, distributed by the GLOBE Project (Hastings and Dunbar 1999).

\section{Analysis methods}

Based on the climatological seasonal march of precipitation and low-tropospheric zonal wind over Vietnam shown by Nguyen-Le et al. $(2014,2015)$, the year could be divided into three seasons: (1) Jan.-Apr. (JFMA), (2) MayAug. (MJJA), and (3) Sept.-Dec. (SOND). In the latter part of the analyses, we focused on season 2, which was the period within which most northern Vietnam heavy-rain days occurred.

Three heavy-rain day definitions have been adopted, based on the VMHA policy of issuing a flood warning in its hydrological forecast when rainfall is greater than $50 \mathrm{~mm}$ day $^{-1}$. In the first definition, a heavy-rain day is a day in which rainfall exceeds $50 \mathrm{~mm}$ at each grid point in the VnGP used in Fig. 2. The second definition is a day when rainfall is greater than $50 \mathrm{~mm}$ in either the VnGP or the GSMaP, at each grid point used in Fig. 3. The third definition is when rainfall greater than $50 \mathrm{~mm}$ day $^{-1}$ in at least one grid point within the analyzed region, in either the VnGP or the GSMaP used in Table 2 and Fig. 6. The latter two definitions were used in the comparison between the two datasets and in the performance evaluation of the GSMaP for heavy-rain cases. The bias of the GSMaP with respect to the VnGP was defined as the mean of the GSMaP minus that of the VnGP, for heavy-rain days, whereas the root mean square difference (RMSD) between the GSMaP and the VnGP was 


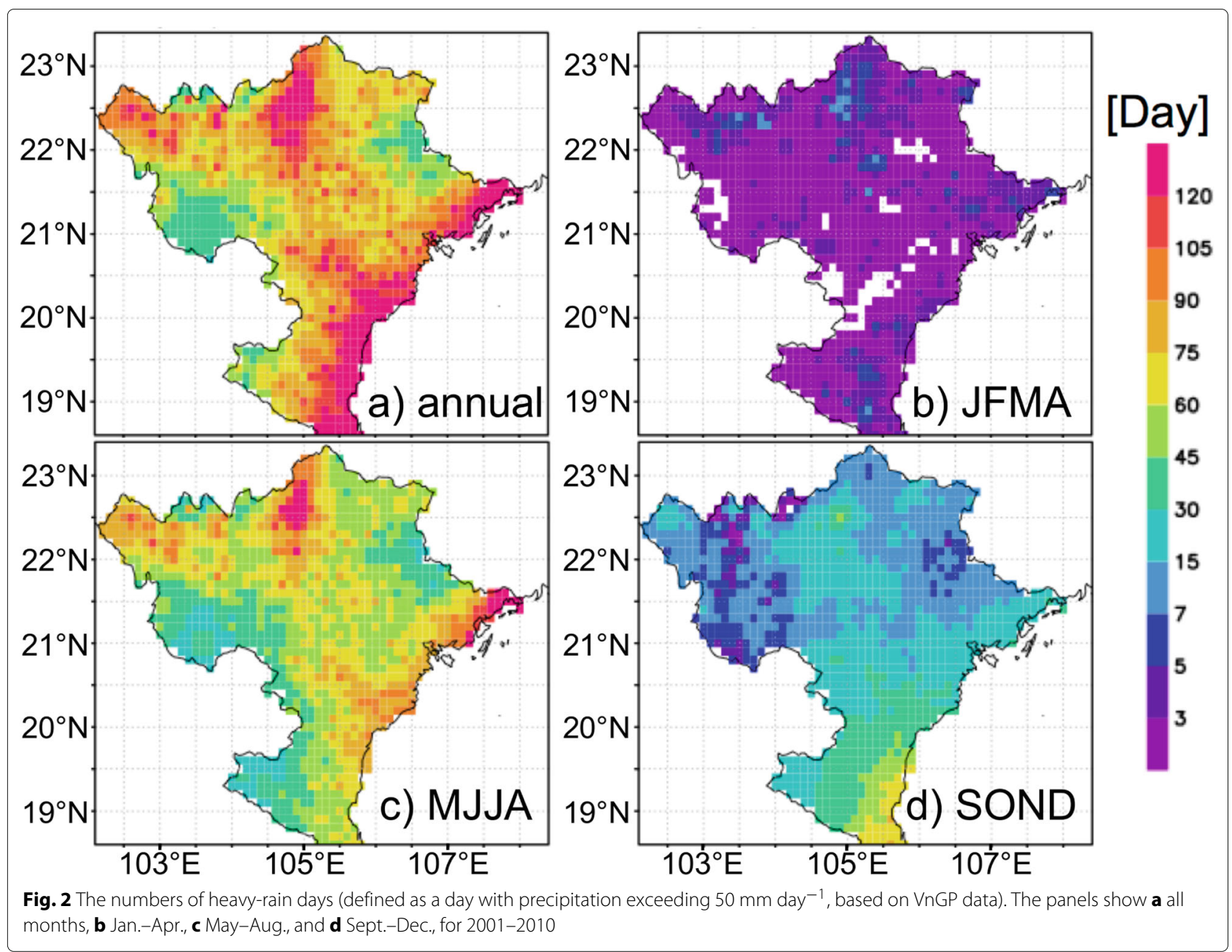

also calculated for heavy-rain days - and these two indices have been displayed in Fig. 3. We defined the ratio of precipitation to that in the VnGP as the GV ratio, to evaluate the precipitation reproducibility by the GSMaP, in Figs. 4, 5, and 6.

\section{Results and discussion}

The northern Vietnam seasonality of the VnGP heavy-rain days has been plotted as Fig. 2. Note that we analyzed heavy-rain days defined only from the VnGP here. In northern Vietnam, the number of such days during 20012010 (Fig. 2a) exceeded 90 in three regions: (1) the western edge of the Hoang Lien Son Mountains (HLSM), along the Da River Basin; (2) the northern mountainous region adjacent to the northern Red River Delta; and (3) the coastal region. On the other hand, the number of heavy-rain days was less than 45 across the hilly regions, with elevations of $\sim 500 \mathrm{~m}$, in the northeastward of the Red River and the southwestern edge in the south of the Da River Basin. The heavy-rain day number distribution varied on a scale of $100 \mathrm{~km}$, across the study area.
In northern Vietnam, the spatial distribution of the number of heavy-rain days (Fig. 2a) is broadly characterized by that in MJJA (Fig. 2c). This can be judged by the more homogeneous distribution and fewer heavy-rain days in JFMA (Fig. 2b) and SOND (Fig. 2d), compared with MJJA. Over the period 2001-2010, there were fewer than 5 heavy-rain days over almost all of northern Vietnam, in JFMA (Fig. 2b), corresponding to the dry season shown by Nguyen-Le et al. (2015). There were more than 60 heavy-rain days over the region adjacent to central Vietnam in SOND (Fig. 2d), and the number of such days decreased with distance from central Vietnam. Based on these results, we have focused on the MJJA period in the following analyses.

\section{GSMaP performance on heavy-rain days}

Figure 3 shows a comparison between MJJA precipitation in the VnGP and the GSMaP. Figure 3a and b show average daily precipitation for all days in MJJA, while Fig. $3 \mathrm{c}-\mathrm{f}$ show results just for heavy-rain days-defined in this case as days when rainfall greater than $50 \mathrm{~mm}$ 

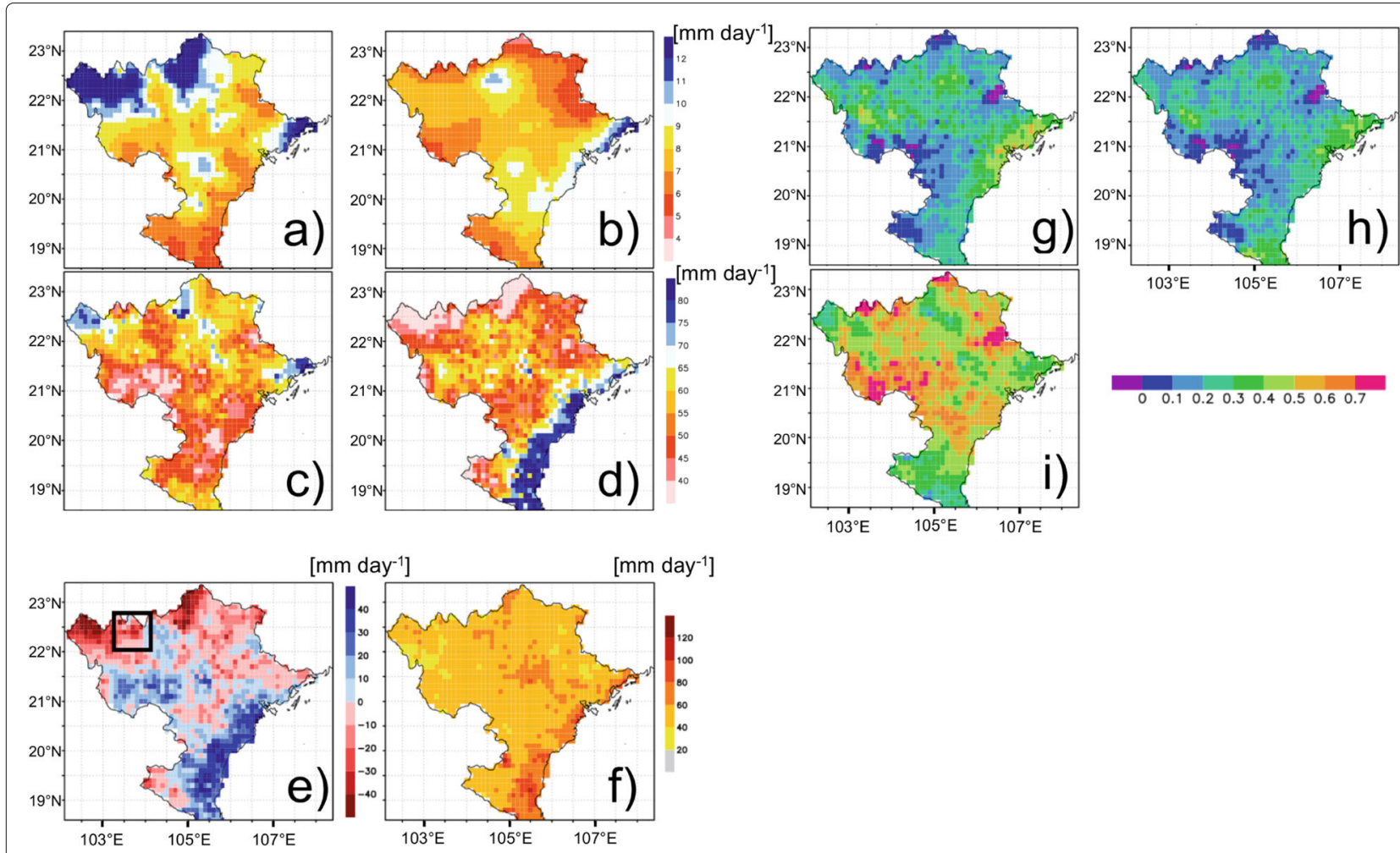

Fig. 3 Distributions of climatological daily precipitation, for heavy-rain days, and its reproducibility by GSMaP over the period of May-Aug., from 2001 to 2010. Daily mean precipitation is shown in $\mathbf{a}$ VnGP and $\mathbf{b}$ GSMaP, for all the analyzed days, and in $\mathbf{c}$ VnGP and $\mathbf{d}$ GSMaP, for heavy-rain days, defined as days with precipitation exceeding $50 \mathrm{~mm}^{\text {day }}{ }^{-1}$ in at least one dataset out of $\mathrm{VnGP}$ or GSMaP, for each grid. Performance of GSMaP on the heavy-rain days shown by e biases were calculated as mean daily precipitation in GSMaP (d), minus that in $\operatorname{VnGP}(\mathbf{c})$, and $\mathbf{f}$ the root mean square difference between GSMaP and VnGP. Categorized forecasts for precipitation exceeding $50 \mathrm{~mm}^{\text {day }}{ }^{-1}$ were verified with $\mathbf{g}$ probability of detection, $\mathbf{h}$ false alarm ratio, and $\mathbf{i}$ equitable threat score. The black rectangle in $\mathbf{e}$ shows the region analyzed in Fig. 6

day $^{-1}$ in either the VnGP or the GSMaP data, at each grid point.

Within northern Vietnam, average daily precipitation records were generally lower in the GSMaP than in the VnGP (Fig. 3a, b). Mean precipitation was greater in the north, in the VnGP, while on the other hand, it was greater along the coast and smaller in the north in the GSMaP. Similar differences in precipitation distribution between the two datasets could be seen in the averages for heavy-rain days (Fig. 3c, d).

Figure 3e shows precipitation biases between the GSMaP and the VnGP, on heavy-rain days. Large negative biases, below $-20 \mathrm{~mm}$ day $^{-1}$, were observed westward of the HLSM and on the northern edge. However, not all inland regions showed negative biases, with some regions having positive biases, of over +20 $\mathrm{mm}$ day $^{-1}$. There were several $100 \mathrm{~km}$ scale regions with either positive or negative biases, and these corresponded approximately to the tributary basin sizes of the upper Red River. The biases were often positive and negative in the regions with smaller and larger precipitation, respectively, on heavy-rain days, in the VnGP (Fig. 3c). This tendency was reflected in a weaker horizontal contrast in the GSMaP (Fig. 3d), than in the VnGP (Fig. 3c), for mean, heavy-rain day precipitation among mountainous regions, in northern Vietnam.

Figure 3 f shows RMSD distribution between the GSMaP and the VnGP for heavy-rain day rainfall: the RMSD showed no marked regionality and ranged between 40-60 $\mathrm{mm} \mathrm{day}^{-1}$ for most grid points within northern Vietnam, except in the coastal region. This result indicated a relatively uniform RMSD distribution, regardless of the large spatial variation in mean precipitation and its biases on heavy-rain days (Fig. 3c-e).

Verification of categorized forecasts for precipitation over $50 \mathrm{~mm}^{\text {day }}{ }^{-1}$ has been shown using probability of detection (POD; Fig. 3g), equitable threat score (ETS; Fig. $3 \mathrm{~h}$ ), and false alarm ratio (FAR; Fig. 3i), by regarding the GSMaP as forecasts for the VnGP. Inland showed small absolute biases, except for the edge regions, which exhibited relatively higher POD and ETS, over 0.2. In addition, the coastal region showed relatively higher POD and ETS, despite large positive biases and RMSD (Fig. 3c-f), implying high temporal consistency in daily precipitation variation. 


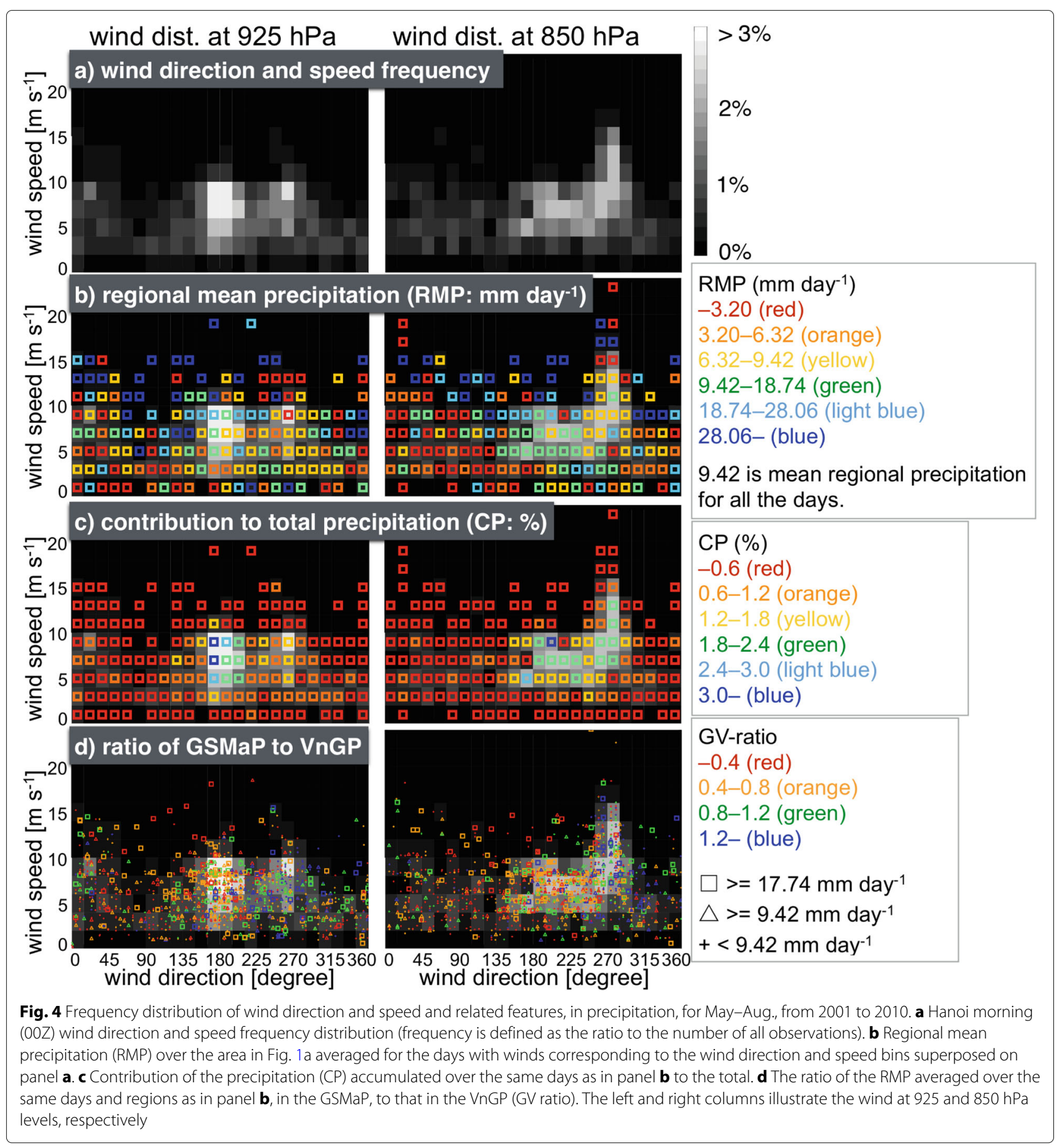

Large positive biases and RMSD seem to be reflected in relatively higher FAR in the central coastal region, around $20.5^{\circ} \mathrm{N}$, and the northern and southwestern edge regions in the inland showed smaller POD and ETS (less than 0.1) and higher FAR (larger than 0.6). The southwestern edge region showed small biases and RMSD so that, in contrast to the case along the coast, temporal consistency was small here.

\section{Relationship between GSMaP performance and wind}

In this section, we describe the relationship between wind and the ratio of precipitation in the GSMaP to that in the VnGP (GV ratio). Previous studies, including Negri and Adler (1993) and Shige et al. (2013), have pointed out the difficulty in estimating precipitation from satellite observations over regions with complex topography in the presence of orographic convection accompanied by 


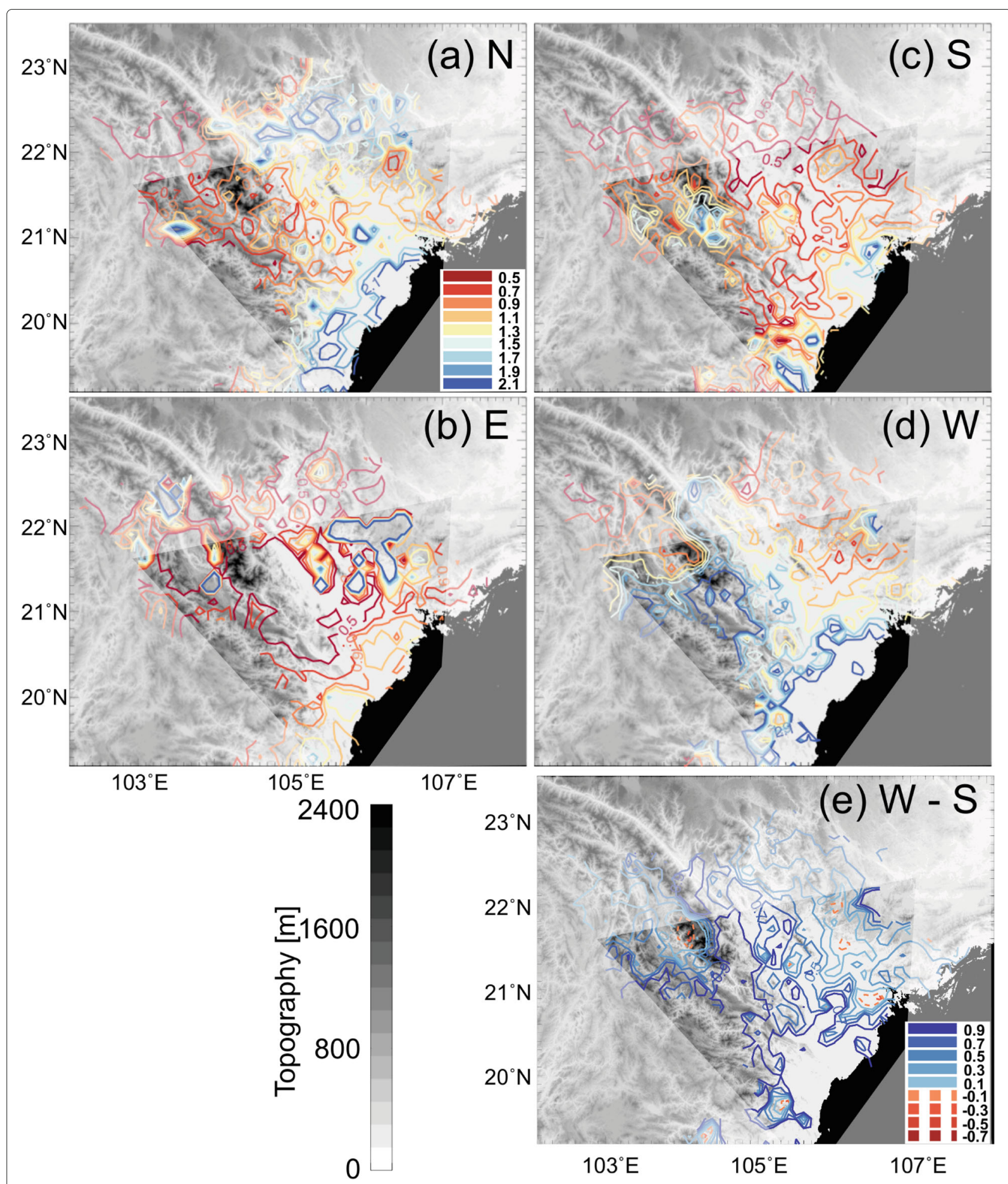

Fig. 5 Horizontal distribution of GSMaP performance for the period May-Aug., in 2000-2010. GV ratios in a northerly, b easterly, c southerly, and d westerly $850 \mathrm{hPa}$ wind cases, at Hanoi, are shown with contours (interval 0.2). The wind direction range in panels $\mathbf{a}, \mathbf{b}, \mathbf{c}$, and $\mathbf{d}$ are $315-360^{\circ}$ and $0-45^{\circ}, 45-135^{\circ}, 135-225^{\circ}$, and $225-315^{\circ}$, respectively. e The difference between $\mathbf{d}$ and $\mathbf{c}$, with contours (interval 0.2 ). Broken and solid lines show negative and positive values, starting at values of ?0.1 and 0.1, respectively. The regions outside the quadrilateral region enclosed by the four Hanoi area radiosonde stations (Vinh, Bach Long Vi, Dien Bien Phu, and Nanning, see Table 2) are shown with paler colors. The four stations show higher correspondence in their zonal wind components with Hanoi, as summarized in Table 2. The horizontal resolution is 0.1 degree 


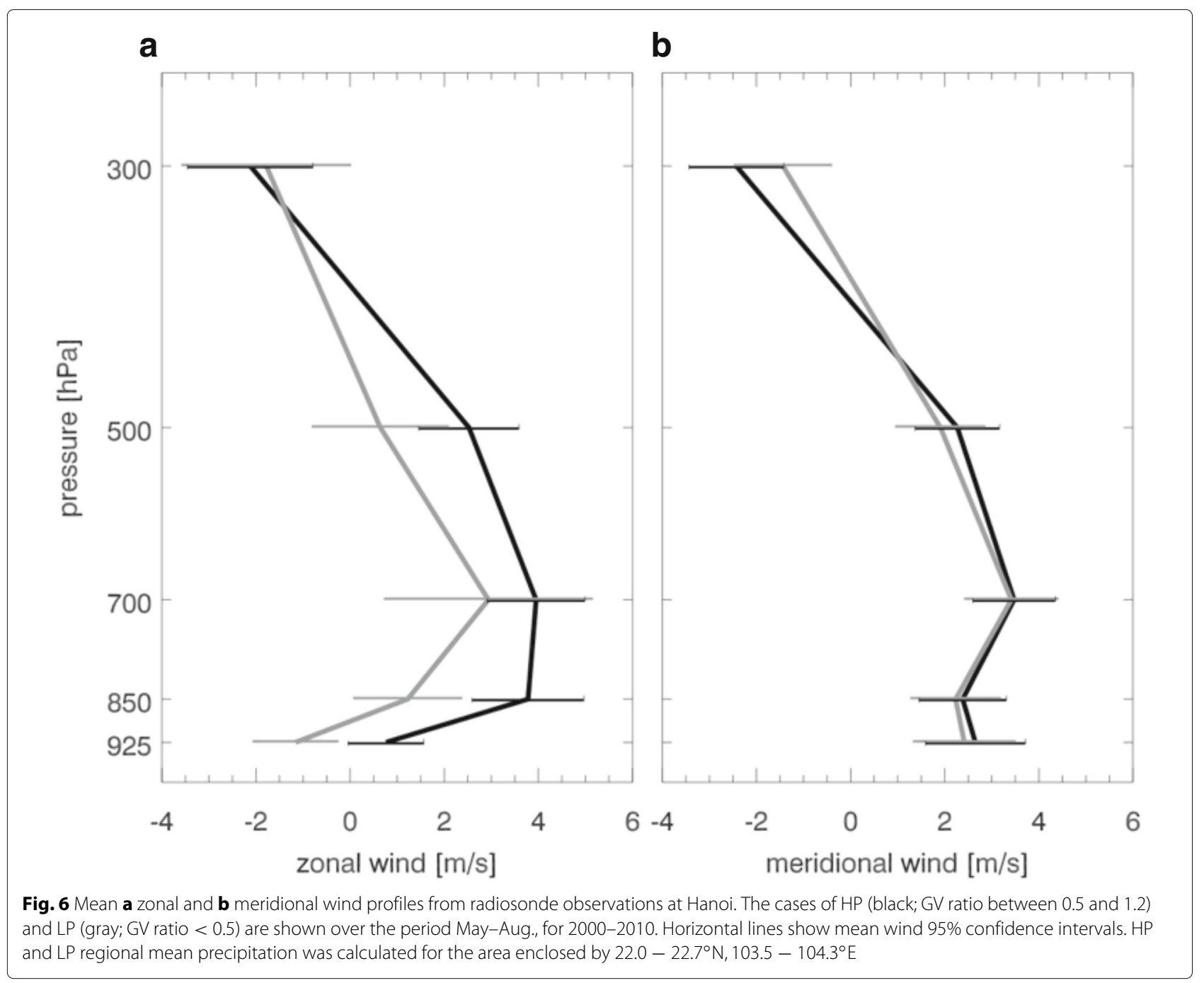

low-tropospheric winds. They made considerable efforts to overcome this problem and achieved great improvements; however, northern Vietnam has very complex topography with several mountain ranges and valleys. It is thus necessary to examine the influence of the interaction between wind and topography on precipitation estimation.

We should note that we compared 0700 LT (0000 UTC) wind data at Hanoi with daily precipitation of up to 1900 LT (1200 UTC). As pointed out by Hirose and Nakamura (2005), rainfall occurs mainly in the late afternoon over northern Vietnam, and it is therefore possible that wind observed in the afternoon is influenced by convection. For example, convection occurred in the westward mountains in northern Vietnam can generate easterly flow. Therefore, we decided that the morning wind would be a more representative, synoptic-scale wind, both in time and space, than the afternoon wind.

First, we confirmed the fundamental climatological relationship between precipitation and wind, in MJJA.
Figure $4 \mathrm{a}$ is a plot showing wind direction, frequency, and speed, for Hanoi, in MJJA, for each wind direction and speed, in $15^{\circ}$ sectors and $2 \mathrm{~m} \mathrm{~s}^{-1}$ steps, respectively. Winds were predominantly southerly to westerly, at both 925 and $850 \mathrm{hPa}$ levels. The winds generally consisted of two groups at the $925 \mathrm{hPa}$ level: southerly winds distributed around $180^{\circ}$ and westerly winds distributed around $270^{\circ}$. It should be noted that the winds were not clearly divided into two groups at the $850 \mathrm{hPa}$ level, and near-westerly winds were more prominent, while above $700 \mathrm{hPa}$, the two groups were not recognizable. Southwesterly and northeasterly winds were dominant at the 700 and $300 \mathrm{hPa}$ levels, respectively, while a slightly westerly focus could be recognized at the $300 \mathrm{hPa}$ level. An intermediate feature can be recognized at the $500 \mathrm{hPa}$ level (not shown).

Regional mean precipitation (RMP) was calculated from the VnGP, over northern Vietnam (apart from the coastal region shown in Fig. 1a) for each wind direction and speed division, with the results plotted as Fig. 4b). We have also 
considered wind and precipitation statistics for cases with wind speed lower than $10 \mathrm{~m} \mathrm{~s}^{-1}$, as shown in Table 1 .

The coastal region was excluded by two reasons. Firstly, GSMaP precipitation biases to the VnGP were largely positive for this region, and secondly, hydrological observations, such as water levels, are more important than rainfall observations in hydrological forecasts for lowlands within a large river delta. Negative values dominated in the biases over the inland region (Fig. 3c-e); thus, in this analysis, we excluded the coastal region, with its large positive biases and whose characteristics were significantly different from the inland region.

The RMP exceeded $9.42 \mathrm{~mm}$ day $^{-1}$ when averaged for all the analyzed days for the near-southerly wind cases when the wind direction was between $135^{\circ}$ and $225^{\circ}$, at the 925 and $850 \mathrm{hPa}$ levels. On the other hand, the RMP was lower in near-westerly wind cases than it was for southerly-wind cases. The mean RMP was higher on southerly wind days $\left(1.5\right.$ and $0.7 \mathrm{~mm}^{\text {day }}{ }^{-1}$ higher at the $925 \mathrm{hPa}$ and $850 \mathrm{hPa}$ levels, respectively) than on westerly wind days, and these differences corresponded to $\sim 10 \%$ of the precipitation mean.

Low RMP values were typically seen in cases where the wind direction was between $30^{\circ}$ and $120^{\circ}$, at the 850 $\mathrm{hPa}$ level (Fig. $4 \mathrm{~b}$ ). The mean RMP on the easterly wind days was $\sim 60 \%$ of the mean precipitation across all analyzed days (Table 1 ). Particularly large RMP values were sometimes seen when the wind exceeds $10 \mathrm{~m} \mathrm{~s}^{-1}$, and it is reasonable to think that such cases occurred under the influence of tropical cyclones. However, extremely low RMP sometimes occurred in association with strong westerly and northerly wind cases, at the $850 \mathrm{hPa}$ level, and a part of these cases could be similar to the downslope, dry Foehn winds reported for central Vietnam by Nguyen-Le et al. (2014).
In Fig. 4c, the contributions of precipitation (CP), accumulated for the analyzed days for each wind direction and speed segment, over the same region as in Fig. 4b, are shown. Note that the values shown in this figure are proportional to those in Fig. 4b, multiplied by the wind frequencies shown in Fig. 4a. Days with near-southerly wind at the $925 \mathrm{hPa}$ level made a major contribution to total precipitation, exceeding $40 \%$ (Table 1). The sectors with large CP (over 1.8\%) were concentrated within the range $165^{\circ}-210^{\circ}$ wind direction, and $4-10 \mathrm{~m} \mathrm{~s}^{-1}$ wind speed (Fig. 4c). On the other hand, the contribution of westerly wind days was $\sim 20 \%$ (Table 1 ), and this difference was mainly because the southerly wind occurred 1.6 times more often than the westerly wind.

In addition, the effect of large RMP cannot be ignored. At the $850 \mathrm{hPa}$ level, the segments with $\mathrm{CP}$ over $1.8 \%$ covered a wider range of southerly and westerly winds (Fig. 4c), and when summed over the corresponding $90^{\circ}$ direction categories, the CPs for southerly and westerly days, with lower wind speed than $10 \mathrm{~m} \mathrm{~s}^{-1}$, were almost equal, at $\sim 30 \%$ (Table 1 ). The contribution from stronger wind speed days than $10 \mathrm{~m} \mathrm{~s}^{-1}$ was relatively small, at both 925 and $850 \mathrm{hPa}$. The results shown in Fig. 4b and c indicated that we should consider the precipitation associated with a wide range of wind directions, from southerly to westerly, at the 925 and $850 \mathrm{hPa}$ levels, when examining relationships with other meteorological phenomena and observations. What is more, it was noteworthy that these two levels had different characteristics - an aspect that should be investigated in the future, being beyond the scope of the present study.

Figure 4d shows the GV ratio plotted for the corresponding wind direction and speed segments over the same region as Fig. 4b, shown in Fig. 1a. Each mark corresponds to the GV ratio and wind on a single day. It can

Table 1 Statistics of wind frequency, precipitation, and its reproducibility by the GSMaP with respect to the VnGP classified into four wind direction categories

\begin{tabular}{|c|c|c|c|c|c|c|c|c|}
\hline \multirow{4}{*}{$\begin{array}{l}\text { Level of the wind } \\
\text { Wind direction (in } \\
\text { degrees) }\end{array}$} & \multirow{4}{*}{$\begin{array}{l}\text { North } \\
\left(315-360^{\circ}\right. \\
\left.0-45^{\circ}\right)\end{array}$} & \multirow{4}{*}{$\begin{array}{l}925 \mathrm{hPa} \\
\text { East } \\
\left(45-135^{\circ}\right)\end{array}$} & \multirow{4}{*}{$\begin{array}{l}\text { South } \\
\left(135-225^{\circ}\right)\end{array}$} & \multirow{4}{*}{$\begin{array}{l}\text { West } \\
\left(225-315^{\circ}\right)\end{array}$} & \multicolumn{2}{|c|}{$850 \mathrm{hPa}$} & \multirow{4}{*}{$\begin{array}{l}\text { South } \\
\left(135-225^{\circ}\right)\end{array}$} & \multirow{4}{*}{$\begin{array}{l}\text { West } \\
\left(225-315^{\circ}\right)\end{array}$} \\
\hline & & & & & North & East & & \\
\hline & & & & & $\left(315-360^{\circ}\right.$ & $\left(45-135^{\circ}\right)$ & & \\
\hline & & & & & $\left.0-45^{\circ}\right)$ & & & \\
\hline Number of days & 195 & 152 & 509 & 322 & 132 & 165 & 366 & 408 \\
\hline $\begin{array}{l}\text { Mean daily precipitation } \\
\left(\mathrm{mm} \text { day }^{-1}\right)\end{array}$ & 7.9 & 8.7 & 9.8 & 8.3 & 8.2 & 6.0 & 10.2 & 9.5 \\
\hline $\begin{array}{l}\text { Contribution to total } \\
\text { precipitation (\%) }\end{array}$ & 12.8 & 11.0 & 41.9 & 22.4 & 9.1 & 8.4 & 31.5 & 32.7 \\
\hline GV ratio & 0.78 & 0.58 & 0.71 & 1.03 & 0.80 & 0.51 & 0.61 & 0.91 \\
\hline $\begin{array}{l}\text { Number of days for wind } \\
\text { speed }>10 \mathrm{~m} \mathrm{~s}^{-1}\end{array}$ & 27 & 14 & 36 & 27 & 20 & 22 & 15 & 154 \\
\hline
\end{tabular}

Wind direction range is $90^{\circ}$ around the true north, east, south, and west in each category. The statistics basically show only the cases with wind speed less than $10 \mathrm{~m} \mathrm{~s}^{-1}$. Days with wind speed greater than $10 \mathrm{~m} \mathrm{~s}^{-1}$ are also shown for reference 
be seen that, at both 925 and $850 \mathrm{hPa}$, there was a generally lower (higher) GV ratio for easterly (westerly) wind situations. However, the lower GV ratio was more frequent at the $850 \mathrm{hPa}$ level than at the $925 \mathrm{hPa}$ level, on southwesterly days for a wind direction of $\sim 225^{\circ}$. The GV ratio characteristic associated with wind speed and direction mentioned above was also seen in different classes of RMP, in the VnGP and wind speed. The winds consisted of the near-southerly wind and near-westerly wind groups, as mentioned above.

Regardless of the existence of the two groups, low and high GV ratio days were symmetrically distributed in the easterly and westerly winds, respectively, at the $925 \mathrm{hPa}$ level, around a wind direction of $200^{\circ}$. On the other hand, days with GV ratio lower than 0.8 were distributed in the southwesterly wind area, at the $850 \mathrm{hPa}$ level, and also in the wind direction range of $200-255^{\circ}$. Higher GV ratio days were predominantly seen in the narrow wind direction range of $255-360^{\circ}$, at the $850 \mathrm{hPa}$ level. Often the GV ratio was higher than 0.8 on the northwesterly wind days, at the 925 and $850 \mathrm{hPa}$ levels. These features were also partially seen in the mean GV ratios for the four wind direction categories, as shown in Table 1.

The GSMaP tended to be higher (lower) than the VnGP in the westerly (easterly) wind cases, at both the 925 and $850 \mathrm{hPa}$ levels. In order to determine the relationships between the performance of the GSMaP, $850 \mathrm{hPa}$ wind, and topography, horizontal distributions of the GV ratio over northern Vietnam were compared and are shown in Fig. 5. We limited our analysis to heavy-rain days with precipitation greater than $50 \mathrm{~mm} \mathrm{day}^{-1}$ in either the VnGP or the GSMaP, at each grid point.

In this analysis, we used wind at the $850 \mathrm{hPa}$ level over Hanoi, which is mainly experienced from the southerly to the westerly directions, as shown in Fig. 4. Here we confirmed the zonal wind similarities between Hanoi and its 6 surrounding radiosonde stations. We have shown values corresponding to probability of detection (cPOD) for the two categories, divided by the median of the zonal wind components $(u)$, by regarding the zonal winds for Hanoi and the comparison stations as observed and forecast values, respectively (Table 2). The cPOD was calculated using radiosonde data for MJJA for 2007-2017: note that we selected the period 2007-2017, instead of the period from 2000-2010 used in our other analyses, as three stations out of the six had almost no observation before 2006. The cPOD was almost over 75\% in 4 stations-Vinh, Dien Bien Phu, Bach Long Vi, and Nanning-for cases in which $u$ was both larger and smaller than the $u$ median at Hanoi at the $850 \mathrm{hPa}$ level. This outcome has been shown in Fig. 5, in which pale colors have been used for the area outside the region enclosed by the above 4 stations, where results were less convincing.

In Additional file 1: Figure S1, we have displayed the results from similar analyses as those represented in Fig. 5c-e, conducted using wind in the JRA-55, for each northern Vietnamese grid. The differences and the RMSD for the wind components, between the JRA-55 and Hanoi radiosonde data, were less than $3 \mathrm{~m} \mathrm{~s}^{-1}$, and between 3-6 $\mathrm{m} \mathrm{s}^{-1}$, at all grid points, respectively. The corresponding POD and FAR values for the westerly and southerly wind cases were $31-94 \%$ and $9-52 \%$, respectively. There were cases with smaller POD or larger FAR in one wind component, but either the westerly or the southerly wind cases showed POD larger than 60\%, and FAR smaller than $30 \%$. We have presented these results in Fig. $5 \mathrm{c}-\mathrm{e}$, by careful contrasting with Additional file 1: Figure S1.

Figure $5 \mathrm{a}-\mathrm{d}$ show the GV-ratio distribution in four wind directions. We have mainly described composites on southerly (Fig. 5c) and westerly (Fig. 5d) wind dayswhich occupied $\sim 72 \%$ of all the analyzed days. The GV

Table 2 Correspondence in zonal wind at the $850 \mathrm{hPa}$ level over Hanoi to those over surrounding stations around Hanoi in heavy-rain days when rainfall is greater than $50 \mathrm{~mm}$ day $^{-1}$ in at least one grid point within the analyzed region shown in Fig. 1a in either VnGP or GSMaP

\begin{tabular}{|c|c|c|c|c|c|}
\hline \multirow[b]{2}{*}{$\begin{array}{l}\text { Compared } \\
\text { radiosonde stations }\end{array}$} & \multirow[b]{2}{*}{ Latitude } & \multirow[b]{2}{*}{ Longitude } & \multicolumn{2}{|c|}{ CPOD for } & \multirow[b]{2}{*}{$\begin{array}{r}\text { Number of } \\
\text { analyzed days }\end{array}$} \\
\hline & & & $\begin{array}{r}\text { Smaller-u days } \\
\text { at Hanoi }\end{array}$ & $\begin{array}{r}\text { Larger-u days } \\
\text { at Hanoi }\end{array}$ & \\
\hline Vinh & $18^{\circ} 41^{\prime}$ & $105^{\circ} 40^{\prime}$ & $74 \%$ & $75 \%$ & 746 \\
\hline Bach Long Vi & $20^{\circ} 08^{\prime}$ & $107^{\circ} 43^{\prime}$ & $80 \%$ & $86 \%$ & 522 \\
\hline Dien Bien Phu & $21^{\circ} 24^{\prime}$ & $103^{\circ} 01^{\prime}$ & $83 \%$ & $84 \%$ & 762 \\
\hline Nanning & $22^{\circ} 38^{\prime}$ & $108^{\circ} 13^{\prime}$ & $79 \%$ & $78 \%$ & 1300 \\
\hline Mengzi & $23^{\circ} 23^{\prime}$ & $103^{\circ} 23^{\prime}$ & $59 \%$ & $59 \%$ & 1293 \\
\hline Baise & $23^{\circ} 54^{\prime}$ & $106^{\circ} 36^{\prime}$ & $68 \%$ & $68 \%$ & 1296 \\
\hline
\end{tabular}

The analyzed months are May, June, July, and August from 2007 to 2017. We show values corresponding to probability of detection (cPOD) by regarding zonal wind component $(u)$ at Hanoi and six compared stations surrounding Hanoi as observed and forecasted values, respectively. Categories for $\mathrm{CPOD}$ are larger and smaller than the $u$ medians, which are decided for the heavy-rain days 
ratio was relatively higher along the coast, for all wind directions.

The GSMaP showed lower precipitation than the VnGP over almost all northern Vietnam, in the case of the southerly wind (Fig. 5c). This result was particularly strong over the northern part of the Red River Delta plain, on the southeastern side of the HLSM, with exceptions seen in the JRA- 55 wind analysis for points $\mathrm{d}, \mathrm{f}$, and $\mathrm{h}$ in Additional file 1: Figure S1, which are far from the Delta and had low POD in the westerly wind. The GV ratio was relatively larger over both the southeastern part of the Red River Delta and the coastal regions adjacent to central Vietnam. The GSMaP has higher precipitation than the VnGP, with a GV ratio over 1.5, along some parts of the coast, and another region with higher precipitation can be seen south of the HLSM.

On the other hand, the GV ratio was larger in the westerly wind case than for the southerly wind case, over almost all northern Vietnamese regions (Fig. 5d). In Fig. $4 \mathrm{~d}$, it can be seen that the regional mean GV ratio was relatively larger for westerly winds, at 850 $\mathrm{hPa}$, and the same characteristics were shared by most grid points within northern Vietnam, as seen in Fig. 5c and $\mathrm{d}$. The GSMaP had substantially higher rainfall than the VnGP over the coast and south of the HLSM (the higher GSMaP rainfall over the coast will be discussed later). There was a higher precipitation GSMaP region in the upstream area of the Red River, although the GSMaP still showed lower rainfall than the VnGP, over the northwestern and northeastern regions. These features were also seen in the analysis with the JRA-55 wind (Additional file 1: Figure S1).

Figure 5e shows the distribution of the GV-ratio differences between the westerly and southerly cases (mean GV ratio in the westerly wind cases (Fig. 5d) minus that in the southerly cases (Fig. 5c), showing that northern Vietnam could be roughly divided into three regions, in terms of this difference. The first was located in the northwestern region, west of the HLSM along the Da River basin: the difference was less than +0.5 , or negative, in this region, which corresponded to the region of low GV ratio, even in the westerly wind case (Fig. 5d). Another region was located along the eastern foot of the HLSM and west of the Red River Delta, where the difference was larger than for the other part of northern Vietnam. Here we examine the GV ratio over the southern edge of the HLSM as an example: the GV ratios were $\sim 1.3$ and 2.1 , in the southerly (Fig. 5c) and westerly (Fig. 5d) wind cases, respectively. Additional file 1: Figure S1 also shows a similar contrast, of large and small difference in GV ratio along the eastern and western foots of the HLSM, respectively.

The negative difference in the western foot of the HLSM, as shown in Fig. 5e, was clearly recognizable only in the case with the JRA-55 wind, at $103.75^{\circ} \mathrm{E}, 21.25^{\circ} \mathrm{N}$
(Additional file 1: Figure S1f), where the difference in the wind from Hanoi radiosonde data was smaller than that at the other points. Another area of negative difference could be observed in a region in the northeast that had a relatively low altitude of $\sim 500 \mathrm{~m}$ (Fig. 5e), but this result could not be clearly observed in the JRA-55 analysis (Additional file 1: Figure S1). Larger (smaller) GV-ratio differences (westerly wind minus southerly wind cases) could be seen at the eastern and southern (western) foots of the steep ranges. This result was shared in the analysis with the JRA-55 wind-which not only produced a similar variation that either westerly or southerly wind cases showed POD larger than $60 \%$ and FAR smaller than $30 \%$, but also produced a mean difference and an RMSD of up to $3 \mathrm{~m} \mathrm{~s}^{-1}$ and $6 \mathrm{~m} \mathrm{~s}^{-1}$, respectively (Additional file 1: Figure S1). These outcomes implied that the GSMaP tended to estimate less precipitation for windward situations than it did to leeward.

A GV ratio larger than 1.3 was widely seen over the northward of the Red River plain, which corresponded with the leeward region in the northerly wind case (Fig. 5a). The GV ratio was generally lower than 1.0 over the western part of the plain, including the HLSM. It should be noted that the rainfall was much less in the GSMaP than in the VnGP, in the southwestern foot of the HLSM. The GV ratio was particularly small for easterly wind cases over most parts of northern Vietnam (Fig. 5b).

We investigated the dependence of GV ratio on the vertical wind profile, with the results shown in Fig. 6 . A reference region bounded by $22.0-22.7^{\circ} \mathrm{N}, 103.5-$ $104.3^{\circ} \mathrm{E}$ has been displayed as the black rectangle in Fig. 3e. This analysis was conducted using the following procedure. First, we calculated daily regional mean precipitation (RMP) for this region, and the GV ratio was defined as the ratio of the daily GSMaP RMP to the daily VnGP. A heavy-rain day was defined as a day with rainfall exceeding $50 \mathrm{~mm} \mathrm{day}^{-1}$ for at least one grid point in either the VnGP or the GSMaP. Finally, in Fig. 6, we show the comparison between the mean vertical wind profiles for cases with higher precipitation (HP; mean GV ratio between 0.5 and 1.2) in the GSMaP, with that for cases of lower precipitation (LP; mean GV ratio $<0.5$ ), on heavy-rain days.

This region is important for hydrological forecasting due to its location in the upstream valley of the Red River and has large GV-ratio differences between the easterly and westerly wind cases, of $\sim+0.7$, as shown in Fig. $5 \mathrm{~b}, \mathrm{~d}$. The region is located at the northeastern foot of the HLSM and is also on the leeward side of the HLSM, with respect to the climatological southwesterly monsoonal wind in the lower troposphere (Matsumoto (1992); Nguyen-Le et al. (2014)).

For HP cases, the mean zonal wind component $(u)$ was significantly larger, in the lower troposphere below the 850 
hPa level, than it was for LP cases. The $u$ was larger at the 700- and 500-hPa levels, in the HP cases, with weak significance. The meridional wind component $(v)$ profile showed southerly wind in both cases, at these levels. No clear differences between the HP and LP cases were seen in either the mean $u$ at the 300-hPa level, or the mean $v$ below the 500 -hPa level. The $v$ was smaller in the HP cases than in the LP, at the 300-hPa level, with weak significance. These results indicate that the zonal wind in the lower troposphere was one of the crucial factors affecting GSMaP precipitation performance, in this region.

\section{Discussion}

In this subsection, we consider why the GV ratio was seen to be generally higher in the leeward regions than in the windward regions and the substantially higher GV ratio seen over the coast.

First, we confirm the relationship between wind direction and GSMaP estimated precipitation. Figure 6 shows that LP and HP were related to easterly and westerly winds, respectively. So, since the analyzed region is located at the eastern foot of the HLSM, LP and HP were related to wind directions that corresponded with windward and leeward, respectively. Therefore, the GSMaP exhibiting relatively higher and lower precipitation than the VnGP was connected with wind directions corresponding to the leeward and the windward, respectively. The mean meridional wind component was positive, in both LP and HP cases. The analyzed region is also located at the southern foot of the northward mountains, hence in the windward side, in the aspect of meridional wind. Consequently, the overall lower precipitation in the GSMaP can be related to the windward location of this region.

It has been suggested by various studies, including Todd and Bailey (1995) and Kubota et al. (2009), that, in precipitation datasets based on satellite observations, microwave radiometer algorithms underestimate heavy rainfall from shallow orographic convection. The GSMaP algorithms are based on microwave radiometer observations from the satellite, thus, the above results and discussion have indicated that it was possible for the scheme implemented by YS15 in the algorithms to not fully correct precipitation underestimation in low-top orographic heavy rain. This hypothetical imperfection in the algorithms was also consistent with the comparable, or smaller, GV ratios in the regions at the southwestern foot of the ranges, in the larger- $u$ cases (Fig. 5b, c), because these are windward regions for the climatologically southwesterly wind, in the summer monsoon. The modification may have been insufficient due to the difficulty in quantifying upward forced motion and orographic convection over the complex topography that includes several mountain ranges and valleys, especially around the HLSM.
The GSMaP RNL version 6 algorithm uses winds below $1.5 \mathrm{~km}$ height, from objectively reanalyzed data, for identification of orographic convection, based on the scheme in YS15. We examined biases and root mean square errors (RMSEs) between JRA-55 and radiosonde data for zonal and meridional winds, at the levels of 925 and $850 \mathrm{hPa}$, at $00 \mathrm{Z}$ and $12 \mathrm{Z}$ (Table 3). The JRA-55 data were interpolated for the Hanoi radiosonde station position, with the data for the four surrounding grids. The sign of the mean zonal wind in the JRA- 55 was different to that in the radiosonde data, at the $850-\mathrm{hPa}$ level, at $12 \mathrm{Z}$. The absolute value of mean meridional wind in the JRA- 55 was less than half that of the radiosonde data, at the $925 \mathrm{hPa}$ level, at 00Z, and as well, the absolute values for the mean zonal wind in the radiosonde data were less than the corresponding RMSEs between the radiosonde and JRA- 55 data. Similar results could be obtained for the meridional winds, at $12 \mathrm{Z}$ at the $850 \mathrm{hPa}$ level and at $00 \mathrm{Z}$ at the $925-\mathrm{hPa}$ level. These results imply that the wind directions in the reanalysis and objective analysis datasets were not reliable for judging upslope winds connected to orographic convection.

Next, we discuss the importance of vapor carried by the southerly wind. It is widely known that active convection in the Asian summer monsoon is strongly governed by southwesterly flow from the Indian Ocean (e.g., Matsumoto (1997)) that contains abundant water vapor sourced from the Indian Ocean. However, by the time it reaches Vietnam, this southwesterly wind has passed over the Indochina Peninsula and lost a substantial amount of its vapor. In fact, the southerly wind cases at 925 and $850 \mathrm{hPa}$ give larger and comparable precipitation amounts, respectively, compared to the southwesterly cases (Fig. 4c). This result implies a similarly important role for the water vapor carried by the southerly wind to that in the southwesterly wind. Water vapor transported

Table 3 Comparison of zonal and meridional wind components in JRA-55 dataset with those in radiosonde dataset at Hanoi

\begin{tabular}{|c|c|c|c|c|c|}
\hline $\begin{array}{l}\text { Level of } \\
\text { the wind }\end{array}$ & Time & $\begin{array}{l}\text { Wind } \\
\text { component }\end{array}$ & $\begin{array}{l}\text { Radiosonde } \\
\text { (renalaysis) mean }\end{array}$ & Bias & RMSE \\
\hline \multirow{4}{*}{$925 \mathrm{hPa}$} & OOUTC & Zonal & $0.84(0.85)$ & +0.01 & 1.94 \\
\hline & $(07 L T)$ & Meridional & $1.87(0.37)$ & -1.50 & 2.74 \\
\hline & $12 \mathrm{UTC}$ & Zonal & $-1.99(-1.41)$ & +0.58 & 2.29 \\
\hline & $(19\llcorner T)$ & Meridional & $3.22(2.11)$ & -1.11 & 2.45 \\
\hline \multirow{4}{*}{$850 \mathrm{hPa}$} & OOUTC & Zonal & $2.73(1.58)$ & -1.15 & 2.84 \\
\hline & $(07 L T)$ & Meridional & $1.19(0.87)$ & -0.31 & 2.19 \\
\hline & 12 UTC & Zonal & $0.36(-0.01)$ & -0.37 & 2.26 \\
\hline & $(19\llcorner T)$ & Meridional & $1.34(1.32)$ & -0.02 & 2.03 \\
\hline
\end{tabular}

The analyzed months are May, June, July, and August from 2000 to 2010. We show means in the both datasets, biases defined as values in the JRA-55 minus those in the radiosonde and root mean square errors $\left(\mathrm{m} \mathrm{s}^{-1}\right)$. The JRA-55 values are interpolated at Hanoi's location with the data at four surrounding grids with inverse-distance-square weighting 
from different wind directions should be analyzed in detail, in future studies. Our study also showed a more severe deficit in the GSMaP precipitation for southerly wind cases (Figs. 4d and 5), and so, therefore, we should fully consider the GSMaP precipitation deficit when it is used in hydrological applications.

Finally, we consider the substantially higher rainfall over the coast in the GSMaP, compared to the VnGP. Nguyen-Xuan et al. (2016) showed the coarse distribution of gauge stations in Vietnam and indicated that the interpolated method, Spheremap, did not always have an advantage in regions with coarse gauge networks. Price et al. (2000) identified unrealistic precipitation maxima at grids between the coast and the inland gauge stations that were neighbors of grids that were without sufficient information on surface rainfall, in spatially interpolated data-and we must assume it is possible that the VnGP also had abnormally low values at grids in similar locations. However, Nguyen-Xuan et al. (2016) showed comparable reproducibility in the three coastal grids with gauge data compared to the other eight inland grids, among the grids showing worse reproducibility than the daily Asian Precipitation-Highly-Resolved Observational Data Integration Towards Evaluation (Yatagai et al. 2012) datasets. Moreover, the higher precipitation in the GSMaP than that in the VnGP was systematically evident in grids inland of gauge stations near the coast, making it difficult to explain the possible lower precipitation in the VnGP through a weak point over coastal areas in an interpolation method. On the other hand, it should be noted that there is room for improvement in the precipitation estimate along the coast, as examined by Mega and Shige (2016), by addressing the difficulties caused by radiometrically intermingled surface features.

\section{Conclusions}

Precipitation accuracy in the GSMaP RNL version 6 was examined by using the VnGP for ground truthing. We also investigated the precipitation dependence and its accuracy in the GSMaP data, on the wind, using operational radiosonde data.

Most heavy-rain days over northern Vietnam were found to occur from May-Aug., with an inhomogeneous horizontal distribution.

The ratio of precipitation in the GSMaP to that in the VnGP exhibited large horizontal variability, especially in the biases over northern Vietnam from May-Aug., on heavy-rain days. Regions with positive and negative biases were intermingled, and there were several horizontal regions, at the scale of $\sim 100 \mathrm{~km}-$ a scale comparable with the size of the upstream tributary basins of the Red River-with similar systematic biases. The lower precipitation in the GSMaP, compared with the VnGP, was most conspicuously seen in the furthest upstream region of the Red River basin and at the north edge of Vietnam. While there were regions with largely negative biases in the mountains, positive biases were widely seen along the coast. The RMSD showed homogeneous distribution over northern Vietnam, with a value of $\sim 50 \mathrm{~mm} \mathrm{day}^{-1}$.

The daily regional mean precipitation (RMP) was greater for nearly southerly winds, at the $925 \mathrm{hPa}$ level, than from other directions, from May-Aug. Greater RMP was also seen with southwesterly winds, at $850 \mathrm{hPa}$, and this tendency was also observed in their accumulated contribution to total precipitation. The GV ratio, defined as a ratio of the GSMaP precipitation to the VnGP precipitation, showed small (large) values for easterly (westerly) wind cases, at $925(850) \mathrm{hPa}$.

The GV ratio was larger for westerly than easterly winds over almost all of northern Vietnam. The GV ratio for the westerly winds greatly exceeded that for easterly winds, especially along the northeastern foot of the HLSM and the western part of the Red River Delta, located at the eastern foot of the mountains. On the other hand, the GV ratio was slightly larger or smaller over the Da River Basin and over the eastern part of the Red River Delta, located at the western foot of the mountains. These results indicated that the GSMaP tended to exhibit higher (lower) precipitation on the leeward (windward) side of the mountains.

Consistent results were obtained from the mean wind profiles classified into relatively higher (HP; GV ratio between 0.5 and 1.2) and lower precipitation (LP; GV ratio below 0.5 ) groups. The profiles showed that the mean zonal wind component was significantly larger (more positive) in the HP cases than in the LP cases, at the 925 and $850 \mathrm{hPa}$ levels.

The results presented here will help improve the northern Vietnam hydrological warning system, including for the Red River Delta, and will progress meteorological investigation into Vietnamese rainfall features and mechanisms (e.g., Takahashi (2013)). Discussions based on our results lead to the hypothesis that the GSMaP scheme, introduced by YS15, cannot fully correct the estimate for low-top orographic convection, using lowlevel winds, from objective reanalysis data over complex topography. One solution to this issue is to use a more accurate wind dataset in evaluation of orographic convection.

We applied the VnGP for ground validation rainfall data in the present study; however, it is challenging to create a reliable interpolated dataset over data-sparse regions, particularly in mountainous regions, indicating that there is room to improve the VnGP in the future, possibly with the aid of surface radar observations. The 3D shapes of clouds, which are controlled by the vertical wind profile, will strongly affect satellite precipitation algorithm performance. This suggests that we should investigate 
the effect of cloud shape on performance, using satellite observations of the vertical profiles of hydrometeors, including clouds and precipitating particles. Such satellite observation times are limited, over any given region, so we should accumulate more cases using groundbased rainfall data and wind data, combining operational radiosonde observation with reanalysis data having higher temporal resolution.

Cloud shapes depend on atmospheric stability, which is governed by vertical temperature and humidity profiles, even in the same level of heavy rainfall (Shige and Kummerow 2016), as well as the wind profile. In future research, we need to improve our understanding of this whole process, including the vertical growth of precipitating clouds influenced by not only the combination of wind and topography, as implied from the present study, but also temperature, humidity, and precipitation.

\section{Additional file}

Additional file 1: Figure S1. Showing the robustness of the horizontal distribution of GSMaP performance shown in Fig. 5. (a) As for Fig. 5c-e. The left, center and right panels correspond to Fig. $5 c$, d, and e, respectively. (b-i) Same as Figure S1a, but for the (left) southerly, and (center) westerly wind, at the $850 \mathrm{hPa}$ level, for eight grid points over and around northern Vietnam, in the JRA-55, and (right) the difference ((center) minus (left)). The eight grid points are shown on the map with the $1.25^{\circ} \times 1.25^{\circ}$ lattice, at the upper right. (PDF 12,276 kb)

\section{Abbreviations}

CP: Contribution of precipitation; DIAS: Data Integration and Analysis System: EORC: Earth Observation Research Center; GLOBE: Global Land One-km Base Elevation; GPM: Global Precipitation Measurement; GSMaP: Global Satellite Mapping of Precipitation; GSMaP RNL: GSMaP data Microwave-Infrared Combined Reanalysis Product; GV ratio: the ratio of precipitation in GSMaP to that in VnGP; HLSM: Hoang Lien Son Mountains; HP: Relatively higher precipitation in the GSMaP than in the VnGP; JAXA: Japan Aerospace Exploration Agency; JFMA: From January to April; LP: Relatively lower precipitation in the GSMaP than in the VnGP; MJJA: From May to August; PMM: Precipitation Measuring Mission; RMP: Regional mean precipitation; RMSD: Root mean square difference; RMSE: Root mean square error; SCS: South China Sea; SOND: From September to December; TRMM: Tropical Rainfall Measuring Mission; TSM: Truong Son Mountains; VMHA: Vietnam Meteorological Hydrological Administration; VnGP: Vietnam Gridded Precipitation

\section{Acknowledgements}

The authors thank Dr. Ko Nakajima for the fruitful discussion on the statistical analysis of wind, and Drs. Fumie Murata, Takuji Kubota, Shoichi Shige, and Munehisa K. Yamamoto for constructive advice and comments. The authors also thank Dr. Misako Kachi for giving information on key features in satellite-based precipitation estimation.

The constructive comments from the three anonymous reviewers led to significant improvements in the manuscript.

This study was supported by the 8th Precipitation Measuring Mission (PMM) Project (PI No. 204) of the Japan Aerospace Exploration Agency (JAXA). GSMaP products were produced and distributed by the EORC, JAXA, under the GSMaP Project, sponsored by JST-CREST, and promoted by the JAXA PMM Science Team. The VnGP dataset was produced mainly under the auspices of project number QG.15.06, by the Vietnam National University, Hanoi, and archived and provided under the DIAS framework, through the National Key Technology, Marine Earth Observation Exploration System. The GLOBE dataset was produced and provided by the Global Land One-km Base Elevation Project, National Geophysical Data Center, NOAA.

\section{Authors' contributions}

MIN proposed the topic; MIN and JM designed research; MIN and LTT performed research and analyzed data; and MIN, JM, LTT, and TND collaborated in constructing and writing the manuscript. All authors read and approved the final manuscript.

\section{Authors' information}

MIN is a research fellow at Tokyo Metropolitan University (nodzum@tmu.ac.jp). $J M$ is the director of the Research Center for Climatology and a professor at the Department of Geography at Tokyo Metropolitan University and a visiting principal scientist at the Japan Agency for Marine-Earth Science and Technology (jun@tmu.ac.jp). LTT was a student at the doctoral program at Tokyo Metropolitan University at the first submission. He came to the Department of Space and Aeronautics of the University of Science and Technology of Hanoi to take up a postdoctoral researcher this April (trinhtuanlong@gmail.com).TND is an associate professor at the Department of Space and Aeronautics of the University of Science and Technology of Hanoi (ngo-duc.thanh@usth.edu.vn).

\section{Funding}

This study was supported by the 8th Precipitation Measuring Mission (PMM) Project (PI No. 204) of the Japan Aerospace Exploration Agency (JAXA). JM and TND were additionally supported by the JSPS KAKENHI Grant Number 26220202 and by Vietnam National Foundation for Science and Technology Development (NAFOSTED) under grant number 105.06-2018.05, respectively.

\section{Availability of data and materials}

VnGP data were secured from the Data Integration and Analysis System (DIAS) site (http://dias-dss.tkl.iis.u-tokyo.ac.jp/dl/storages/filelist/dataset:271). The GSMaP RNL version 6 data were obtained from the FTP site of JAXA and are available, following registration, at (http://sharaku.eorc.jaxa.jp/GSMaP/ registration.html). Radiosonde observation data were obtained from the Atmospheric Soundings site (http://weather.uwyo.edu/upperair/sounding. html) by the University of Wyoming. GLOBE data were obtained from the site of the Global Land One-km Base Elevation Project, by the National Oceanic and Atmospheric Administration (NOAA), from the site shown in the reference.

\section{Competing interests}

The authors declare that they have no competing interests.

\section{Author details}

${ }^{1}$ Department of Geography, Tokyo Metropolitan University, 1-1 Minami Ohsawa, Hachioji, Tokyo 192-0397, Japan. ${ }^{2}$ Dynamic Coupling of Ocean-Atmosphere-Land Research Program, Japan Agency for Marine Earth Science and Technology, 2-15 Natsushima-cho, Yokosuka, Kanagawa 237-0061, Japan. ${ }^{3}$ REMOSAT Laboratory, University of Science and Technology of Hanoi, Vietnam Academy of Science and Technology, 18 Hoang Quoc Viet Str., Cau Giay, Ha Noi, Vietnam.

Received: 19 December 2017 Accepted: 5 July 2019

Published online: 26 August 2019

\section{References}

Aonashi K, Awaka J, Hirose M, Kozu T, Kubota T, Liu G, Shige S, Kida S, Seto S, Takahashi N, Takayabu YN (2009) GSMaP passive microwave precipitation retrieval algorithm: algorithm description and validation. J Meteor Soc Japan 87A:119-136. https://doi.org/10.2151/jmsj.87A.119

Chang C-P, Wang Z, McBride J, Liu C-H (2005) Annual cycle of Southeast Asia-Maritime Continent rainfall and the asymmetric monsoon transition. J Climate 18:287-301. https://doi.org/10.1175/jcli-3257.1

Harada Y, Kamahori H, Kobayashi C, Endo H, Kobayashi S, Ota Y, Onda H, Onogi K, Miyaoka K, Takahashi K (2016) The JRA-55 reanalysis: representation of atmospheric circulation and climate variability. J Meteor Soc Japan 94:269-302. https://doi.org/10.2151/jmsj.2016-015

Hastings DA, Dunbar PK (1999) Global Land One-kilometer Base Elevation (GLOBE) digital elevation model, version 1.0. National Oceanic and Atmospheric Administration, National Geophysical Data Center, digital media. Available online at http://www.ngdc.noaa.gov/mgg/topo/globe.html. Accessed 12 Feb 2017

Hirose M, Nakamura K (2005) Spatial and diurnal variation of precipitation systems over Asia observed by the TRMM Precipitation Radar. J Geophys Res 110. https://doi.org/10.1029/2004JD004815 
Kubota T, Shige S, Hashizume H, Aonashi K, Takahashi N, Seto S, Hirose M, Takayabu YN, Nakagawa K, Iwanami K, Ushio T, Kachi M, Okamoto K (2007) Global precipitation map using satellite-borne microwave radiometers by the GSMaP Project: Production and validation. IEEE Trans Geosci Remote Sens 45(7):2259-2275. https://doi.org/10.1109/tgrs.2007.895337

Kubota T, Ushio T, Shige S, Kida S, Kachi M, Okamoto K (2009) Verification of high resolution satellite-based rainfall estimates around Japan using gauge-calibrated ground radar dataset. J Meteor Soc Japan 87A:203-222. https://doi.org/10.2151/jmsj.87A.203

Kobayashi S, Ota Y, Harada Y, Ebita A, Moriya M, Onda H, Onogi K, Kamahori H, Kobayashi C, Endo H, Miyaoka K, Takahashi K (2015) The JRA-55 reanalysis: representation of atmospheric circulation and climate variability. J Meteor Soc Japan 93:5-48. https://doi.org/10.2151/jmsj.2015-001

Kummerow C, Barnes W, Kozu T, Shuie J, Simpson J (1998) The Tropical Rainfall Measuring Mission (TRMM) sensor package. J Atmos Oceanic Technol 15:809-817. https://doi.org/10.1175/1520-0426(1998)015,0809:TTRMMT.2. $0 . \mathrm{CO} ; 2$

Kwon E-H, Sohn B-J, Chang D-E, Ahn M-H, Yang S (2008) Use of numerical forecasts for improving TMI rain retrievals over the mountainous area in Korea. J Appl Meteor Climatol 47:1995-2007. https://doi.org/10.1175/ 2007jamc1857.1

Maggioni V, Massari C (2018) On the performance of satellite precipitation products in riverine flood modeling: a review. J Hydrol 558:214-224. https://doi.org/10.1016/j.jhydrol.2018.01.039

Matsumoto J (1992) The seasonal change in Asian and Australian monsoon regions. J Meteor Soc Japan 70:257-273. https://doi.org/10.2151/jmsj1965. 70.1 b_257

Matsumoto J (1997) Seasonal transition of summer rainy season over Indochina and adjacent monsoon region. Adv Atmos Sci 14:231-245. https://doi.org/10.1007/s00376-997-0022-0

Mega T, Shige S (2016) Improvements of rain/no-rain classification methods for microwave radiometer over coasts by dynamic surface-type classification. J Atmos Oceanic Technol 33:1257-1270. https://doi.org/10. 1175/JTECH-D-15-0127.1

McCollum JR, Ferraro RR (2005) Microwave rainfall estimation over coasts. J Atmos Oceanic Technol 22:497-512. https://doi.org/10.1175/JTECH1732.1

Negri AJ, Adler RF (1993) An intercomparison of three satellite infrared rainfall techniques over Japan and surrounding waters. J Appl Meteor Climatol 32:357-373. https://doi.org/10.1175/1520-0450(1993)032<0357:aiotsi>2.0. $\mathrm{co} ; 2$

Ngo-Duc T, Matsumoto J, Kamimera H, Bui H-H (2013) Monthly adjustment of Global Satellite Mapping of Precipitation (GSMaP) data over the VuGia-ThuBon River basin in Central Vietnam using an artificial neural network. Hydrol Res Lett 7:85-90. https://doi.org/10.3178/hrl.7.85

Nguyen-Le D, Matsumoto J, Ngo-Duc T (2014) Climatological onset date of summer monsoon in Vietnam. Int J Climatol 34:3237-3250. https://doi. org/10.1002/joc.3908

Nguyen-Le, D, Matsumoto J, Ngo-Duc T (2015) Onset of the rainy seasons in the eastern Indochina Peninsula. J Climate 28:5645-5666. https://doi.org/ 10.1175/jcli-d-14-00373.1

Nguyen-Thi HA, Matsumoto J, Ngo-Duc T, Endo N (2012) A climatological study of tropical cyclone rainfall in Vietnam. SOLA 8:041-044. https://doi. org/10.2151/sola.2012-011

Nguyen-Xuan T, Ngo-Duc T, Kamimera H, Trinh-Tuan L, Matsumoto J, Inoue T, Phan-Van T (2016) The Vietnam Gridded Precipitation (VnGP) dataset: construction and validation. SOLA 12:291-296. https://doi.org/10.2151/ sola.2016-057

Price DT, McKenney DW, Nalder IA, Hutchinson MF, Kesteven JK (2000) A comparison of two statistical methods for spatial interpolation of Canadian monthly mean climate data. Agric For Meteor 101:81-94. https://doi.org/ 10.1016/S0168-1923(99)00169-0

Shepard D (1968) A two-dimensional interpolation function for irregularly-spaced data. In: Proc. 1968 ACM Nat'l. Conf. pp 517-524. https:// doi.org/10.1145/800186.810616

Shige S, Kida S, Ashiwake H, Kubota T, Aonashi K (2013) Improvement of TMI rain retrievals in mountainous areas. J Appl Meteor Climatol 52:242-254. https://doi.org/10.1175/jamc-d-12-074.1

Shige S, Kummerow CD (2016) Precipitation-top heights of heavy orographic rainfall in the Asian monsoon region. J Atmos Sci 73:3009-3024. https:// doi.org/10.1175/JAS-D-15-0271.1
Takahashi HG (2013) Orographic low-level clouds of Southeast Asia during the cold surges of the winter monsoon. Atmos Res 131:22-33. https://doi.org/ 10.1016/j.atmosres.2012.07.005

Todd MC, Bailey JO (1995) Estimates of rainfall over the United Kingdom and surrounding seas from the SSM/I using the polarization corrected temperature algorithm. J Appl Meteor 34:1254-1265. https://doi.org/10. 1175/1520-0450(1995)034<1254:eorotu>2.0.co;2

Trinh-Tuan L, Matsumoto J, Ngo-Duc T, Nodzu MI, Inoue T (2019) Evaluation of satellite precipitation products over central Vietnam. Prog Earth Planet Sci 6:54. https://doi.org/10.1186/s40645-019-0297-7

Ushio T, Kubota T, Shige S, Okamoto K, Aonashi K, Inoue T, Takahashi N, Iguchi T, Kachi M, Oki R, Morimoto T, Kawasaki Z (2009) A Kalman filter approach to the Global Satellite Mapping of Precipitation (GSMaP) from combined passive microwave and infrared radiometric data. J Meteor Soc Japan 87A:137-151. https://doi.org/10.2151/jmsj.87A.137

Wang B, LinHo (2002) Rainy season of the Asian-Pacific summer monsoon. J Climate 15:386-398. https://doi.org/10.1175/1520-0442(2002)015<0386: rsotap> 2.0.co;2

Willmott CJ, Rowe CM, Philpot WD (1985) Small-scale climate maps: a sensitivity analysis of some common assumptions associated with grid-point interpolation and contouring. Am Cartographer 12:5-16. https://doi.org/10.1559/15230485783914686

Yamamoto MK, Shige S (2015) Implementation of an orographic/nonorographic rainfall classification scheme in the GSMaP algorithm for microwave radiometers. Atmos Res 163:36-47. https://doi. org/10.1016/j.atmosres.2014.07.024

Yatagai A, Kamiguchi K, Arakawa O, Hamada A, Yasutomi N, Kitoh A (2012) APHRODITE: Constructing a long-term daily gridded precipitation dataset for Asia based on a dense network of rain gauges. Bull Amer Meteor Soc 93:1401-1415. https://doi.org//10.1175/BAMS-D-11-00122.1

Zhang Y, Li T, Wang B, Wu G (2002) Onset of the summer monsoon over the Indochina Peninsula: Climatology and interannual variations. J Climate 15:3206-3221. https://doi.org/10.1175/1520-0442(2002)015<3206: ootsmo> 2.0.co; 2

\section{Publisher's Note}

Springer Nature remains neutral with regard to jurisdictional claims in published maps and institutional affiliations.

\section{Submit your manuscript to a SpringerOpen ${ }^{\circ}$ journal and benefit from:}

- Convenient online submission

- Rigorous peer review

- Open access: articles freely available online

- High visibility within the field

- Retaining the copyright to your article

Submit your next manuscript at $>$ springeropen.com 